\title{
Biosynthesis of $\boldsymbol{\gamma}$-linolenic acid in cotyledons and microsomal preparations of the developing seeds of common borage (Borago officinalis)
}

\author{
Sten STYMNE* $\ddagger$ and Allan Keith STOBART $\dagger$ \\ *Department of Food Hygiene, Swedish University of Agricultural Sciences, P.O. Box 7009, S-750 07 Uppsala, Sweden, and \\ †Department of Botany, University of Bristol, Bristol BS8 1UG, U.K.
}

\begin{abstract}
The developing seeds of Borago officinalis (common borage) accumulate a triacylglycerol oil that is relatively rich in the uncommon fatty acid $\gamma$-linolenate (octadec-6,9,12-trienoic acid). Incubation of developing, whole, cotyledons with $\left[{ }^{14} \mathrm{C}\right]$ oleate and $\left[{ }^{14} \mathrm{C}\right]$ linoleate showed that the $\gamma$-linolenate was synthesized by the sequential desaturation of oleate $\rightarrow$ linoleate $\rightarrow \gamma$-linolenate. Microsomal membrane preparations from the developing cotyledons contained an active $\Delta^{6}$-desaturase enzyme that catalysed the conversion of linoleate into $\gamma$-linolenate. Experiments were designed to manipulate the $\left[{ }^{14} \mathrm{C}\right]$ linoleate content of the microsomal phosphatidylcholine. The $\left[{ }^{14} \mathrm{C}\right]$ linoleoyl phosphatidylcholine labelled in situ was converted into $\gamma$-linolenoyl phosphatidylcholine in the presence of NADH. The substrate for the $\Delta^{6}$-desaturase in borage was, therefore, the linoleate in the complex microsomal lipid phosphatidylcholine, rather than, as in animals, the acyl-CoA. This was further confirmed in experiments that compared the specific radioactivity of the $\gamma$-linolenate, in acyl-CoA and phosphatidylcholine, that was synthesized when $\left[{ }^{14} \mathrm{C}\right]$ linoleoyl-CoA was incubated with microsomal membranes, NADH and non-radioactive $\gamma$-linolenoyl-CoA. The $\Delta^{6}$-desaturase was positionally specific and only utilized the linoleate in position 2 of $s n$-phosphatidylcholine. Analysis of the positional distribution of fatty acids in the endogenous microsomal $s n$-phosphatidylcholine showed that, whereas position 1 contained substantial linoleate, only small amounts of $\gamma$-linolenate were present. The results shed further light on the synthesis of $\mathrm{C}_{18}$ polyunsaturated fatty acids in plants and in particular its relationship to the regulation of the acyl quality of the triacylglycerols in oilseeds.
\end{abstract}

\section{INTRODUCTION}

In animals the activity of the $\Delta^{6}$-desaturase enzyme that catalyses the conversion of linoleic acid (octadeca9,12-dienoic acid) into $\gamma$-linolenic acid (octadeca-6,9,12trienoic acid) is thought to be affected by certain dietary (Brenner, 1981) and clinical conditions (Holman \& Johnson, 1981). The dietary application of vegetable oils rich in $\gamma$-linolenate is considered (Horrobin \& Manku, 1983) to alleviate hypercholesterolaemia and many atopic disorders. Unfortunately, only a few plant species are known that produce $\gamma$-linolenate in sufficient quantities for commercial exploitation. The major sources of plant $\gamma$-linolenate are the seed oils of evening primrose (Oenothera biennis) (Hilditch \& Williams, 1964) and the common borage (Borago officinalis) (Tetenyi et al., 1974) and the fruits of Ribes spp. (currant) (Traitler et al., 1984). To date nothing is known about the biosynthesis in plants of the $\Delta^{6}$ isomer of linolenic acid, and yet its appreciation as an essential fatty acid and its popularity in the health-food industry has increased considerably in the last few years. It is important to establish, therefore, for plant-breeding programmes, how $\gamma$-linolenic acid is synthesized and the relationship of this to the formation of the seed triacylglycerols.

The occurrence of $\alpha$-linolenic acid (octadeca-9,12,15trienoic acid) is quite widespread in oilseeds and it is also a major component of photosynthetic membranes. It is thought that the substrate for the synthesis of $\alpha$-linolenate in seeds (Browse \& Slack, 1981) and leaves (Roughan et al., 1979; Hawke \& Stumpf, 1980; Jones \& Harwood, $1980)$ is the linoleate in phosphatidylcholine and monogalactosyldiacylglycerol respectively. The evidence for this, particularly in oilseeds, is still rather poor, since this tissue has proved somewhat recalcitrant in providing consistently active membrane preparations for studies on the synthesis of $\alpha$-linolenate. On the other hand, the evidence that the oleate (octadec-9-enoic acid) in microsomal phosphatidylcholine is the substrate for linoleate synthesis in plant tissues is overwhelming (Stymne \& Appelqvist, 1978; Slack et al., 1979; Stymne et al., 1983; Murphy et al., 1985). The synthesis of linoleate and, most likely, $\alpha$-linolenate, occurs therefore in plants in complex lipid substrates, whereas $\gamma$-linolenate synthesis in animals (Holloway, 1983) utilizes the CoA ester directly. The reason why higher plants should favour complex lipid substrates for $\mathbf{C}_{18}$ polyunsaturated fatty acid synthesis is unclear. We have speculated (Stymne \& Stobart, 1986), for experimental purposes, that the efficient insertion of a double bond between the methyl end of $\mathrm{C}_{18}$ fatty acid and an already established centre of unsaturation, as occurs in plants, may require the intramolecular environment of a complex lipid. On the other hand the introduction of double bonds between an existing double bond and the carboxy end of a fatty acid molecule may necessitate, as in animals, the involvement of acyl-CoA. It has been previously proposed (Howling et al., 1972) that the plant desaturase enzymes which catalyse the formation of linoleate from

$\ddagger$ To whom correspondence and reprint requests should be sent. 
oleate may utilize both the acyl-CoA and phosphatidylcholine substrates. A study of the mode of $\gamma$-linolenate synthesis in plants was therefore undertaken to test these suggestions and also to increase our understanding of $\mathrm{C}_{18}$ polyunsaturated fatty acid formation for the possible manipulation of the acyl quality of the seed oils. We report here for the first time studies on the formation of $\gamma$-linolenic acid in plants and, in particular, its synthesis in microsomal membrane preparations from the maturating cotyledons of Borago officinalis.

\section{MATERIALS AND METHODS}

\section{Chemicals}

$\left[1-{ }^{14} \mathrm{C}\right]$ Stearic acid (octadecanoic acid), $\left[1-{ }^{14} \mathrm{C}\right]$ oleic acid (octadec-9-enoic acid) and $\left[1-{ }^{14} \mathrm{C}\right]$ linoleic acid (octadeca9,12-dienoic acid) were obtained from The Radiochemical Centre, Amersham, Bucks., U.K. Catalase (thymol-free, 11000 units/mg), bovine serum albumin (fraction V, fatty acid free), CoASH, NADH, phospholipase $\mathrm{A}_{2}$ [from Indian cobra (Naja naja) venom] and various fatty acids were purchased from Sigma. SEP-PAK $C_{18}$ silica-gel cartridges were from Waters Associates, Farmington, MA, U.S.A.

Heptadecanoyl-CoA, $\left[1-{ }^{14} \mathrm{C}\right]$ linoleoyl-CoA (sp. radioactivity 2597 d.p.m./nmol) and $\gamma$-linolenoyl-CoA (octadeca-6,9,12-trienoyl-CoA) were synthesized from their mixed anhydrides as described by Sanchez et al. (1973). The radioactive acyl-CoA had a purity greater than $97 \%$ as determined by t.l.c., g.l.c. and radio-g.l.c.

\section{Plant material and microsomal preparations}

Borago officinalis L. (common borage) seeds were purchased from Weibulls, Landskrona, Sweden, and for the experiments in vivo the plants were grown in a greenhouse during the 1985 summer period. The flowers were hand-pollinated and developing seeds harvested 15-20 days after flowering. For the experiments in vitro, however, it was found essential to cultivate the plants in a controlled environment. These plants were therefore grown in a $16 \mathrm{~h}$ photoperiod at $18^{\circ} \mathrm{C}$ and an $8 \mathrm{~h}$ night at $13^{\circ} \mathrm{C}$.

Cotyledons (approx. $5 \mathrm{mg}$ fresh weight/cotyledon pair) were removed from the developing seeds and stored in ice-cold $0.1 \mathrm{M}$-potassium phosphate buffer, $\mathrm{pH} 7.2$, containing $0.3 \mathrm{M}$-sucrose. All further procedures were carried out at $1-4{ }^{\circ} \mathrm{C}$. The cotyledons were ground in a mortar with 2 parts $(\mathrm{v} / \mathrm{w})$ of 0.1 M-potassium phosphate buffer, $\mathrm{pH} 7.2$, containing $0.1 \%$ bovine serum albumin, $0.33 \mathrm{M}$-sucrose and 1000 units of catalase $/ \mathrm{ml}$. The homogenate was diluted 20 -fold with fresh grinding medium and filtered through a double layer of Miracloth before centrifugation at $20000 \mathrm{~g}$ for $10 \mathrm{~min}$. The supernatant was refiltered through Miracloth and centrifuged at $105000 \mathrm{~g}$ for $90 \mathrm{~min}$. The resulting microsomal pellet was resuspended in the homogenization medium and either used directly or stored at $-70^{\circ} \mathrm{C}$ (for up to 3 days only) before use.

\section{Enzyme assays}

In the experiments in vivo, whole cotyledons were incubated (five pairs; approx. $25 \mathrm{mg}$ fresh weight) for $30 \mathrm{~min}$ at $25^{\circ} \mathrm{C}$ with the ammonium salt of either $\left[{ }^{14} \mathrm{C}\right]$ oleate or $\left[{ }^{14} \mathrm{C}\right]$ linoleate $(15.9 \mathrm{nmol}$; sp. radioactivity $1: 26 \times 10^{5}$ d.p.m. $/ \mathrm{nmol}$ in each case) in $0.25 \mathrm{ml}$ of
0.1 M-phosphate buffer, $\mathrm{pH}$ 7.2. After that time the cotyledons were rinsed in buffer to remove residual radioisotope and extracted with an Ultra-Turrax homogenizer in the medium described by Bligh \& Dyer (1959) or further incubated in fresh buffer for various times before extraction.

Microsomal assays were carried out at $25^{\circ} \mathrm{C}$ with constant shaking. The incubation mixtures contained $10 \mathrm{mg}$ of bovine serum albumin, 1000 units of catalase, $66 \mathrm{~mm}$-sucrose, substrates and cofactors (as given in the Tables) and microsomal membranes in a final volume of $1 \mathrm{ml}$ with $0.1 \mathrm{M}$-phosphate buffer. All the incubations were carried out in complete darkness, since light was found to have an adverse effect on the desaturase activity in the microsomes.

\section{Analytical procedures}

Reactions were terminated by the addition of $0.15 \mathrm{M}$-acetic acid and the lipids extracted by a modification of the medium described by Bligh \& Dyer (1959). The lower chloroform phase, which contains the complex lipids and the non-esterified fatty acids, was removed and evaporated to dryness under $\mathrm{N}_{2}$. The residue was dissolved in a small volume of chloroform and the polar and neutral lipids were purified by t.l.c. on precoated silica-gel plates (Merck; silica-gel 60) with chloroform/methanol/acetic acid/water (170:30:20:7, by vol.) or hexane/diethyl ether/acetic acid (70:30:1, by vol.) respectively. Lipid areas, located by lightly staining with $I_{2}$ vapour, were removed from the plates and either assayed for radioactivity or methylated in situ with methanolic $2.5 \%$ (w/w) $\mathrm{HCl}$ (Kates, 1964) for the analysis of the fatty acids. The fatty acid methyl esters were analysed by g.l.c. with a glass column $(2 \mathrm{~m} \times 2 \mathrm{~mm})$ containing $10 \%$ BDS on Chromosorb W (HP, 80-100 mesh) and quantified by using methylheptadecanoic acid as an internal standard or analysed by radio-g.l.c. for the determination of the radioactivity in the fatty acids.

Methyl esters of $\gamma$-linolenic acid were authenticated by co-chromatography with standard methyl $\gamma$-linolenate in the g.l.c. system given above. The retention times of methyl $\alpha$-linolenate and methyl $\gamma$-linolenate, relative to the internal standard methyl heptadecanoate, were 1.96 and 1.80 respectively. Further authentication was achieved by argentation t.l.c. in which the methyl $\gamma$-linolenate from seed lipid samples co-chromatographed with trienoate standards. Trace amounts of $\mathrm{C}_{20: 1}, \mathrm{C}_{22: 1}$ (erucic acid) and $\mathrm{C}_{24: 1}$ (nervonic acid), present in the seed triacylglycerol, were tentatively identified according to their retention times during g.l.c. relative to authentic standards.

Positional analysis of the fatty acids in phosphatidylcholine was performed by treatment of the lipid with phospholipase $\mathrm{A}_{2}$ as previously described (Griffiths et al., 1985).

Where the analysis of the acyl-CoA was required, the incubation mixture was supplied with heptadecanoylCoA $(100 \mathrm{nmol})$, as an internal standard, immediately before the reactions were terminated and the lipids extracted. The methanol/water phase from the Bligh \& Dyer (1959) extraction, which contained all the acyl-CoA, was freed from protein by passing it through a $\mathrm{C}_{18}$ silica-gel cartridge as previously described (Stymne \& Glad, 1981). The acyl-CoA fraction was further purified by t.l.c. in butan-1-ol/acetic acid/water $(5: 2: 3$, by vol.) (Stymne \& Stobart, 1985). The gel containing the 
Table 1. Fatty acid composition of the major complex lipids in the developing cotyledons of borage

The results are the means of two determinations \pm S.E.M.

Composition (\%)

\begin{tabular}{|c|c|c|c|c|c|c|c|}
\hline Lipid & $\begin{array}{l}\text { Fatty } \\
\text { acid ... }\end{array}$ & $C_{16: 0}$ & $\mathrm{C}_{18: 0}$ & $\mathrm{C}_{18: 1}$ & $C_{18: 2}$ & $\mathrm{C}_{\gamma-18: 3}$ & $\mathrm{C}_{20: 1}$ \\
\hline $\begin{array}{l}\text { Phosphatidylcholine } \\
\text { Phosphatidylethanolamine } \\
\text { Diacylglycerol } \\
\text { Triacylglycerol* }\end{array}$ & & $\begin{array}{l}20 \pm 1 \\
25 \pm 2 \\
19 \pm 1 \\
16 \pm 1\end{array}$ & $\begin{array}{l}5 \pm 2 \\
3 \pm 1 \\
6 \pm 1 \\
6 \pm 1\end{array}$ & $\begin{array}{r}20 \pm 1 \\
7 \pm 1 \\
21 \pm 2 \\
28 \pm 3\end{array}$ & $\begin{array}{l}39 \pm 1 \\
55 \pm 4 \\
37 \pm 1 \\
33 \pm 2\end{array}$ & $\begin{array}{r}15 \pm 1 \\
9 \pm 1 \\
16 \pm 2 \\
17 \pm 1\end{array}$ & $\begin{array}{l}1 \pm 0.5 \\
1 \pm 0.5 \\
1 \pm 0.5 \\
\text { Trace }\end{array}$ \\
\hline
\end{tabular}

acyl-CoA was removed and the fatty acids methylated in situ with sodium methoxide. The methyl esters were analysed by g.l.c. and radio-g.l.c. as described above. When the specific radioactivity of the methyl esters from the acyl-CoA was required methyl $\left[{ }^{14} \mathrm{C}\right]$ stearate of known specific radioactivity (2045 d.p.m./nmol) was used as an internal standard and co-chromatographed with the sample during the analysis by g.l.c. and radio-g.l.c. It should be noted that no methyl stearate was originally present in the sample.

Lipid samples were assayed for radioactivity in PCS (Amersham/Searle)/xylene $(2: 1, \mathrm{v} / \mathrm{v})$ scintillant in a Beckman LS-230 liquid-scintillation counter with an efficiency of $94 \%$ for ${ }^{14} \mathrm{C}$. All radioactivity counts were corrected for background and quenching.

\section{RESULTS}

The acyl composition of the major complex lipids in the developing cotyledons of plants grown under greenhouse conditions is given in Table 1. All the lipids examined contained substantial quantities of $\gamma$-linolenate. It is noteworthy that the relative distribution of fatty acids in phosphatidylcholine was almost identical with that of the diacylglycerol, and this supports the view that these lipids are in equilibrium during the synthesis of triacylglycerols, as observed in oilseeds of some other species (Slack et al., 1983; Stobart \& Stymne, 1985a). The relative abundance of $\gamma$-linolenate in triacylglycerol was also similar to that in phosphatidylcholine and diacylglycerol. This would indicate that some $\gamma$-linolenate is being utilized in the third acylation step in the final formation of the triacylglycerol. It is also of interest that the triacylglycerol also contained small quantities of erucic acid $\left(C_{22: 1}\right)$ and nervonic acid $\left(C_{24: 1}\right)$ (results not shown).

\section{Utilization of $\left[{ }^{14} \mathrm{C}\right]$ oleate and $\left[{ }^{14} \mathrm{C}\right]$ linoleate in the synthesis of $\boldsymbol{y}$-linolenate in cotyledons of borage}

The intact and developing cotyledons (batches of five pairs; approx. $25 \mathrm{mg}$ ) were incubated with the ammonium salt of either $\left[{ }^{14} \mathrm{C}\right]$ oleic acid or $\left[{ }^{14} \mathrm{C}\right]$ linoleic acid for $30 \mathrm{~min}$. After that time the cotyledons were thoroughly washed in phosphate buffer, $\mathrm{pH} 7.2$, to remove residual isotope and either extracted immediately for the analysis of lipids or resuspended in fresh buffer for further incubation. At regular intervals after the removal of the excess isotope samples were again taken for analysis. The incorporation of radioactive substrates into the lipid fraction varied slightly between samples (Table 2), as would be expected in experiments in vivo that utilize whole tissues. Because of this difference the results for the distribution of radioactivity in the major lipids are presented as relative values (Table 2). The results show that, even after 30 min incubation in either substrate, the major lipids under investigation (phosphatidylcholine, diacylglycerol and triacylglycerol) contained most of the radioactivity, with the major part being present in the triacylglycerols at all times. After removal of the exogenous $\left[{ }^{14} \mathrm{C}\right]$ substrate and subsequent transfer to buffer, similar general trends of radioactive incorporation were observed in both the oleate- and linoleate-fed tissues. The relative amount of radioactivity in triacylglycerol generally increased, whereas that in phosphatidylcholine dramatically declined. The relative radioactivity in the diacylglycerol, on the other hand, remained constant. Complex lipids, other than those given in Table 2 , contained $4 \%$ or less of the total radioactivity found in the lipid fraction at all incubation times.

To ascertain whether $\gamma$-linolenate was synthesized from $\left[{ }^{14} \mathrm{C}\right]$ oleate and $\left[{ }^{14} \mathrm{C}\right]$ linoleate, the distribution of radioactivity in the $\mathrm{C}_{18}$ unsaturated fatty acids present in the complex lipids was determined (Table 3 ). The results show that the $\left[{ }^{14} \mathrm{C}\right]$ oleate was efficiently desaturated to linoleate and $\gamma$-linolenate and that the $\gamma$-linolenate accumulated in all the complex lipids that were analysed. The $\left[{ }^{14} \mathrm{C}\right]$ linoleate-fed tissues accumulated even greater quantities of radioactive $\gamma$-linolenate, and again this was found to acccumulate in the complex lipids. The results strongly suggest that the $\gamma$-linolenate was synthesized in a sequential fashion from oleate and linoleate, but gave, however, no indication of the true substrate(s) involved.

An analysis of the intramolecular positional distribution of the ${ }^{14} \mathrm{C}$-labelled fatty acids in the $s n$ phosphatidylcholine obtained from the cotyledons that had been incubated with $\left[{ }^{14} \mathrm{C}\right]$ linoleate showed that $\left[{ }^{14} \mathrm{C}\right]$ linoleate was present at the 1 and 2 positions of sn-phosphatidylcholine (26 and $56 \%$ of the total radioactivity respectively). Radioactive $\gamma$-linolenate was, however, only found in position $2(18 \%$ of the total radioactivity) of $s n$-phosphatidylcholine. The observation that the $\Delta^{6}$-desaturase did not appear to utilize substrate at position $s n-1$ of $s n$-phosphatidylcholine was given further support from positional analysis of the relative distribution of fatty acid species present in the endogenous microsomal complex lipid. $\gamma$-Linolenate was found in abundance at position $s n-2$ of phospha- 
Table 2. Incorporation of radioactivity into various lipids in the intact cotyledons of borage incubated in either $\left[{ }^{14} \mathrm{C}\right]$ oleate or $\left[{ }^{14}\right.$ Cllinoleate

Intact cotyledons (fresh weight $25 \mathrm{mg}$ ) were incubated with the ammonium salt of either $\left[{ }^{14} \mathrm{C}\right]$ oleate or $\left[{ }^{14} \mathrm{C}\right]$ linoleate $(15.9 \mathrm{nmol}$; sp. radioactivity $1.26 \times 10^{5} \mathrm{~d}$.p.m./nmol in each case) for $30 \mathrm{~min}$. The cotyledons were then rinsed to remove residual label and resuspended in fresh buffer. At regular intervals thereafter the cotyledons were extracted and the radioactivity determined in the individual lipids. For experimental details, see the Materials and methods section.

\begin{tabular}{|c|c|c|c|c|c|}
\hline \multirow[b]{2}{*}{ Substrate } & \multirow{2}{*}{$\begin{array}{l}\text { Incubation } \\
\text { time } \\
\text { (h) }\end{array}$} & \multirow{2}{*}{$\begin{array}{c}{ }^{14} \mathrm{C} \text { incorporation into } \\
\text { total complex lipids } \\
\text { (nmol) }\end{array}$} & \multicolumn{3}{|c|}{$\begin{array}{l}\text { Radioactive distribution among the } \\
\text { complex lipids }(\%)\end{array}$} \\
\hline & & & $\begin{array}{l}\text { Phosphatidyl- } \\
\text { choline }\end{array}$ & $\begin{array}{l}\text { Diacyl- } \\
\text { glycerol }\end{array}$ & $\begin{array}{l}\text { Triacyl- } \\
\text { glycerol }\end{array}$ \\
\hline$\left[{ }^{14} \mathrm{C}\right]$ Oleate & $\begin{array}{l}0.5 \\
1 \\
2 \\
3 \\
4\end{array}$ & $\begin{array}{l}6.4 \\
4.5 \\
7.6 \\
7.8 \\
6.8\end{array}$ & $\begin{array}{r}22 \\
15 \\
10 \\
6 \\
4\end{array}$ & $\begin{array}{l}25 \\
22 \\
19 \\
20 \\
19\end{array}$ & $\begin{array}{l}36 \\
49 \\
52 \\
62 \\
64\end{array}$ \\
\hline$\left[{ }^{14} \mathrm{C}\right]$ Linoleate & $\begin{array}{l}0.5 \\
1 \\
2 \\
3 \\
4\end{array}$ & $\begin{array}{l}8.1 \\
5.7 \\
8.8 \\
9.4 \\
7.2\end{array}$ & $\begin{array}{r}17 \\
14 \\
8 \\
5 \\
4\end{array}$ & $\begin{array}{l}23 \\
20 \\
18 \\
20 \\
19\end{array}$ & $\begin{array}{l}46 \\
44 \\
65 \\
65 \\
68\end{array}$ \\
\hline
\end{tabular}

tidylcholine $(32 \%)$, with only trace amounts $(<2 \%)$ at the $s n-1$ position. On the other hand, both positions of $s n$-phosphatidylcholine contained substantial oleate (15 and $21 \%$ in positions $s n-1$ and $s n-2$ respectively) and linoleate $(39$ and $47 \%$ in positions $s n-1$ and $s n-2$ respectively).

\section{Desaturation of $\left[{ }^{14} \mathrm{C}\right]$ linoleate in cell-free preparations from developing cotyledons}

The previous experiments in vivo failed to give an indication of the true substrate (acyl-CoA versus complex lipid) for the synthesis of $\gamma$-linolenate. In order to study, therefore, the kinetics of $\gamma$-linolenate formation in greater detail, it was essential to obtain cell-free fractions from the developing cotyledons of borage that were active in producing this fatty acid. A number of experiments with seeds of different age and different homogenization and assay conditions were carried out to optimize, as far as possible, the linoleate $\Delta^{6}$-desaturase activity in the microsomal preparations. Treatments that enhanced and stabilized the desaturase (see the Materials and methods section) were the inclusion of catalase in the homogenization buffer and in the assay mixtures, the use of bovine serum albumin in the reaction mixtures and the enzyme assays carried out in the absence of light. The addition of NADH was essential for the desaturation of linoleate in the microsomal preparations. Microsomal preparations from the developing cotyledons at stages older than 20 days after flowering ( $>6 \mathrm{mg}$ fresh weight/cotyledon pair) gave poor and irreproducible desaturase activity.

Preliminary experiments showed that the microsomal preparations were active in transferring substantial amounts of the $\left[{ }^{14} \mathrm{C}\right]$ linoleate in acyl-CoA to phosphatidylcholine. Other observations indicated that a major proportion of synthesized $\gamma-\left[{ }^{14} \mathrm{C}\right]$ linolenate also resided in the microsomal phosphatidylcholine (results not shown). These preliminary results bore a close resemblance to the utilization of the $\left[{ }^{14} \mathrm{C}\right]$ oleoyl-CoA and its desaturation to radioactive linoleate observed in microsomal phosphatidylcholine in preparations from the oilseeds of other species (Stymne \& Appelqvist, 1978; Stobart et al., 1983; Stymne \& Stobart, 1984b). Experiments were therefore carried out to establish whether $\left[{ }^{14} \mathrm{C}\right]$ linoleoyl phosphatidylcholine labelled in situ could be desaturated to $\gamma-\left[{ }^{14} \mathrm{C}\right]$ linolenoyl phosphatidylcholine. Microsomal preparations from borage cotyledons were incubated with $\left[{ }^{14} \mathrm{C}\right]$ linoleoyl-CoA in the presence of free CoA and bovine serum albumin under non-desaturating conditions (minus NADH) for $20 \mathrm{~min}$. Free CoA and bovine serum albumin were included in the reaction mixture, since they promote the reversible transfer of fatty acids between position 2 of $s n$ phosphatidylcholine and the pool of acyl-CoA, a process that is probably catalysed by an acyl-CoA:lysophosphatidylcholine acyltransferase (Stymne \& Stobart, $1984 a, 1985)$. The transfer of $\left[{ }^{14} \mathrm{C}\right]$ linoleate in acyl-CoA to the microsomal phosphatidylcholine was terminated after $20 \mathrm{~min}$ incubation by diluting the incubation mixture with cold homogenization buffer. The microsomal membranes were recovered by a further centrifugation. The washing of the membranes in fresh buffer removed almost totally the $\left[{ }^{14} \mathrm{C}\right] \mathrm{acyl}-\mathrm{CoA}$ substrate and any non-esterified fatty acids that had been generated during the incubation period. Some $70 \%$ of the radioactivity in the pretreated and washed microsomes resided in phosphatidylcholine, of which all was $\left[{ }^{14} \mathrm{C}\right]$ linoleate (Table 4). Aliquots of the $\left[{ }^{14} \mathrm{C}\right]$ linoleatelabelled microsomes (equivalent to $86 \mathrm{nmol}$ of phosphatidylcholine) were incubated further for 20 and 80 min under both non-desaturating and desaturating (plus NADH) conditions. At these times the radioactive linoleate and $\gamma$-linolenate were determined in phosphatidylcholine (Table 4). The results show that appreciable $\left[{ }^{14} \mathrm{C}\right]$ linoleate was present in phosphatidylcholine, with no $\gamma-\left[{ }^{14} \mathrm{C}\right]$ linolenate in any of the incubations minus NADH. On the addition of NADH, however, $\gamma=\left[{ }^{14} \mathrm{C}\right]$ linolenate appeared in the phosphatidylcholine and this accumulated with further incubation. In fact 20 and $80 \mathrm{~min}$ after the addition of NADH some 14 and $28 \%$ of the 


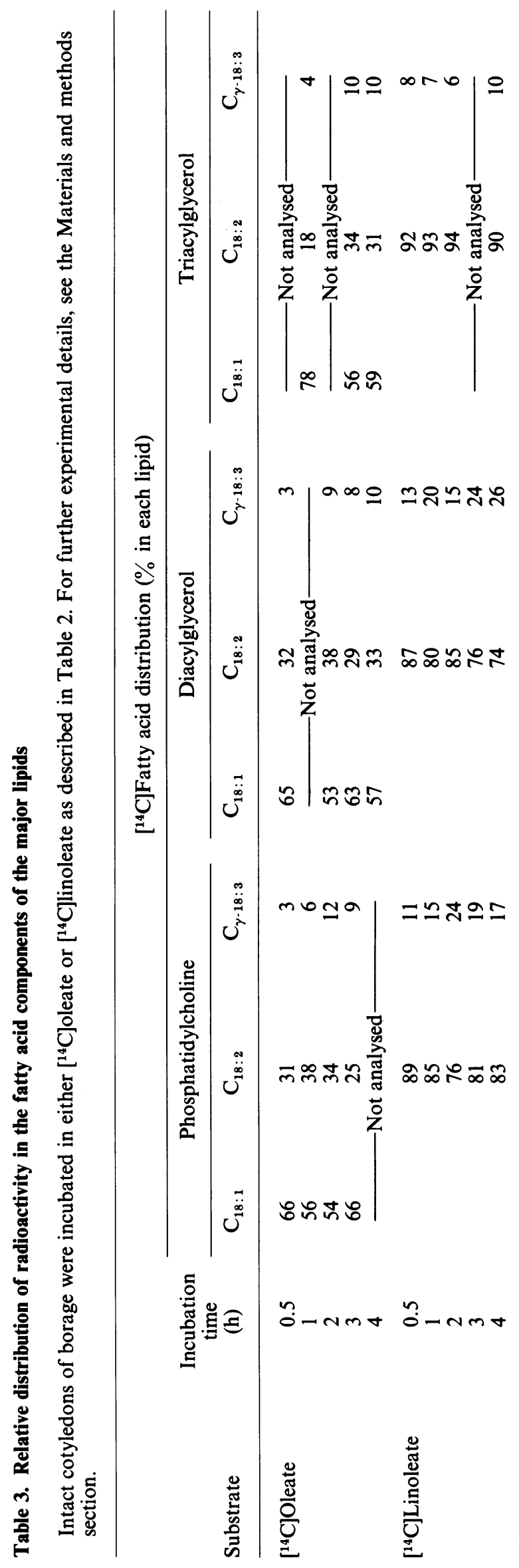


Table 4. Desaturation of $\left[{ }^{14} \mathrm{C}\right.$ linoleoyl phosphatidylcholine labelled in situ in microsomal preparations from the developing cotyledons of borage

Microsomal preparations (equivalent to $860 \mathrm{nmol}$ of phosphatidylcholine) were prelabelled with [ $\left.{ }^{14} \mathrm{C}\right]$ linoleate by incubation for $20 \mathrm{~min}$ at $25^{\circ} \mathrm{C}$ with $400 \mathrm{nmol}$ of $\left[{ }^{14} \mathrm{C}\right]$ linoleoyl-CoA, $400 \mathrm{nmol}$ of $\mathrm{CoA}$ and $20 \mathrm{mg}$ of bovine serum albumin in $0.1 \mathrm{M}$-phosphate buffer, $\mathrm{pH} 7.2$, in a total volume of $2 \mathrm{ml}$. The reaction mixture was then diluted to $25 \mathrm{ml}$ with cold homogenization buffer and the microsomes collected by centrifugation at $105000 \mathrm{~g}$ for $60 \mathrm{~min}$. After resuspension of the microsomes, aliquots (equivalent to $86 \mathrm{nmol}$ of phosphatidylcholine) were incubated with $(2 \mu \mathrm{mol})$ or without NADH for the times stated in the Table. Results are, where indicated, the means \pm S.E.M. for two incubations.

$\left[{ }^{14} \mathrm{C}\right]$ Radioactivity (nmol)

\begin{tabular}{|c|c|c|c|c|c|c|c|}
\hline \multirow{2}{*}{$\begin{array}{c}\text { Incubation } \\
\text { time } \\
\text { (min) }\end{array}$} & \multirow[b]{2}{*}{ NADH } & \multicolumn{2}{|c|}{ Phosphatidylcholine } & \multirow{2}{*}{$\begin{array}{l}\text { Non-esterified } \\
\text { fatty acids }\end{array}$} & \multicolumn{3}{|c|}{ Other complex lipids } \\
\hline & & $\mathrm{C}_{18: 2}$ & $\mathrm{C}_{\gamma-18: 3}$ & & $\mathrm{C}_{18: 2}$ & & $\mathrm{C}_{\gamma-18: 3}$ \\
\hline 0 & - & 12.7 & 0 & $0.1^{*}$ & \multirow{5}{*}{\multicolumn{2}{|c|}{$\begin{array}{l}5.3 \pm 0^{*} \\
5.7 \pm 0^{*} \\
5.3 \pm 0^{*}\end{array}$}} & 0 \\
\hline 20 & - & $11.8 \pm 0$ & 0 & $0.2 \pm 0^{*}$ & & & \\
\hline 80 & - & $9.7 \pm 0.3$ & 0 & $0.4 \pm 0.1^{*}$ & & & \\
\hline 20 & + & $10.1 \pm 0.1$ & $1.7 \pm 0.1$ & $0.2 \pm 0 *$ & & & \\
\hline 80 & + & $7.6 \pm 0.1$ & $3.0 \pm 0.1$ & $0.5 \pm 0^{*}$ & & & $1.1 \pm 0.1$ \\
\hline
\end{tabular}

radioactivity in phosphatidylcholine was present in $\gamma$-linolenate respectively. After 80 min incubation with $\mathrm{NADH}, 16 \%$ of the radioactivity in the remaining complex lipids was also in $\gamma$-linolenate.

A quantitative analysis of the fatty acids in the microsomal phosphatidylcholine in the incubations was also carried out (Table 5). The results show that the major fatty acid in phosphatidylcholine in the untreated microsomal preparations was linoleate and that oleate and $\gamma$-linolenate amounted to 15 and $18 \%$ of the acyl species present respectively. The mass of linoleate in phosphatidylcholine increased in microsomes pretreated with $\left[{ }^{14} \mathrm{C}\right]$ linoleoyl-CoA. After the addition of NADH, however, there was an increase in the mass of $\gamma$-linolenate from 16 to $19 \%$ after $20 \mathrm{~min}$ incubation and this reached $24 \%$ after $80 \mathrm{~min}$. The increase in the mass of $\gamma$-linolenate was concomitant with the desaturation of $\left[{ }^{14} \mathrm{C}\right]$ linoleate to yield radioactive $\gamma$-linolenate (see Table 4). It should be noted that little change was observed in the fatty acid pattern of phosphatidylcholine in incubations lacking NADH and that no significant change in the total mass of the microsomal phosphatidylcholine had occurred. It is also of interest that, upon the addition of NADH, the oleate in phosphatidylcholine decreased from $14 \%$ at zero time to $6 \%$ after $80 \mathrm{~min}$ incubation (Table 5). Under the conditions of these experiments, little change was observed in the mass of linoleate in phosphatidylcholine during desaturation. A proportion of the $\gamma=\left[{ }^{14} \mathrm{C}\right]$ linolenate (approx. $25 \%$ ) that was produced in the microsomes upon the addition of NADH and at the prolonged incubation time was also associated with complex lipids other than phosphatidylcholine (Table 4). It is also of interest that the total radioactivity in phosphatidylcholine declined somewhat after $80 \mathrm{~min}$ incubation under both desaturating and non-desaturating conditions (Table 4).

The kinetics of the desaturation in situ (see above) were consistent with the activity of a linoleoyl phosphatidylcholine $\Delta^{6}$-desaturase enzyme in the microsomal membranes. It could still be argued, however, that the $\left[{ }^{14} \mathrm{C}\right]$ linoleate, in these experiments, may have been transferred from the phosphatidylcholine to acyl-CoA and there desaturated to $\gamma-\left[{ }^{14} \mathrm{C}\right]$ linolenate, which, in its turn, was rapidly re-incorporated back into the complex lipid. In order to assess this possibility, experiments were designed in which active microsomal membranes were incubated with $\left[{ }^{14} \mathrm{C}\right]$ linoleoyl-CoA and non-radioactive $\gamma$-linolenoyl-CoA in the presence of NADH. The rationale for this was that, if the linoleate $\Delta^{6}$-desaturase enzyme utilized the acyl-CoA substrate, then the newly formed $\gamma-\left[{ }^{14} \mathrm{C}\right]$ linolenoyl-CoA would be rapidly diluted by the large amount of added non-radioactive $\gamma$ linolenoyl-CoA. Hence the subsequent incorporation of $\gamma-\left[{ }^{14} \mathrm{C}\right]$ linolenate from acyl-CoA to the phosphatidylcholine would be from a pool of $\gamma$-linolenate with a lowered specific radioactivity. The specific radioactivity of the $\gamma-\left[{ }^{14} \mathrm{C}\right]$ linolenate transferred to phosphatidylcholine would be even further decreased by the endogenous $\gamma$-linolenate present in this complex lipid. The specific radioactivity of the $\gamma$-linolenate would therefore be greater in the acyl-CoA fraction than in the phosphatidylcholine. If, on the other hand, the $\gamma$-linolenate was synthesized in phosphatidylcholine, then its specific radioactivity would be greater in the complex lipid than in the pool of acyl-CoA.

In a typical experiment a microsomal preparation (equivalent to $192 \mathrm{nmol}$ of phosphatidylcholine) was incubated with $65 \mathrm{nmol}$ of $\left[{ }^{14} \mathrm{C}\right]$ linoleoyl-CoA and $100 \mathrm{nmol}$ of non-radioactive $\gamma$-linolenoyl-CoA under desaturating conditions. After $\mathbf{4 0}$ and $90 \mathrm{~min}$ incubation the radioactive distribution of $\left[{ }^{14} \mathrm{C}\right]$ linoleate and $\gamma$ $\left[{ }^{14} \mathrm{C}\right]$ linolenate and their specific radioactivity were determined in the acyl-CoA fraction, phosphatidylcholine and the total remaining complex lipids. The results (Table 6) showed that, after $\mathbf{4 0} \mathrm{min}$ incubation, some $14 \%$ of the radioactivity in the phosphatidylcholine was present as $\gamma-\left[{ }^{14} \mathrm{C}\right]$ linoleate and this was equivalent to 2 mol of desaturated $\left[{ }^{14} \mathrm{C}\right]$ linoleate substrate. At that incubation time no $\gamma=\left[{ }^{14} \mathrm{C}\right]$ linolenate was detected in the acyl-CoA fraction, although some $60 \mathrm{nmol}$ of the non-radioactive $\gamma$-linolenoyl-CoA was still present (Table 6). At the longer incubation time the $\gamma$ $\left[{ }^{14} \mathrm{C}\right]$ linolenate in phosphatidylcholine had increased to $23 \%$ (equivalent to $5.5 \mathrm{nmol}$ of desaturated 


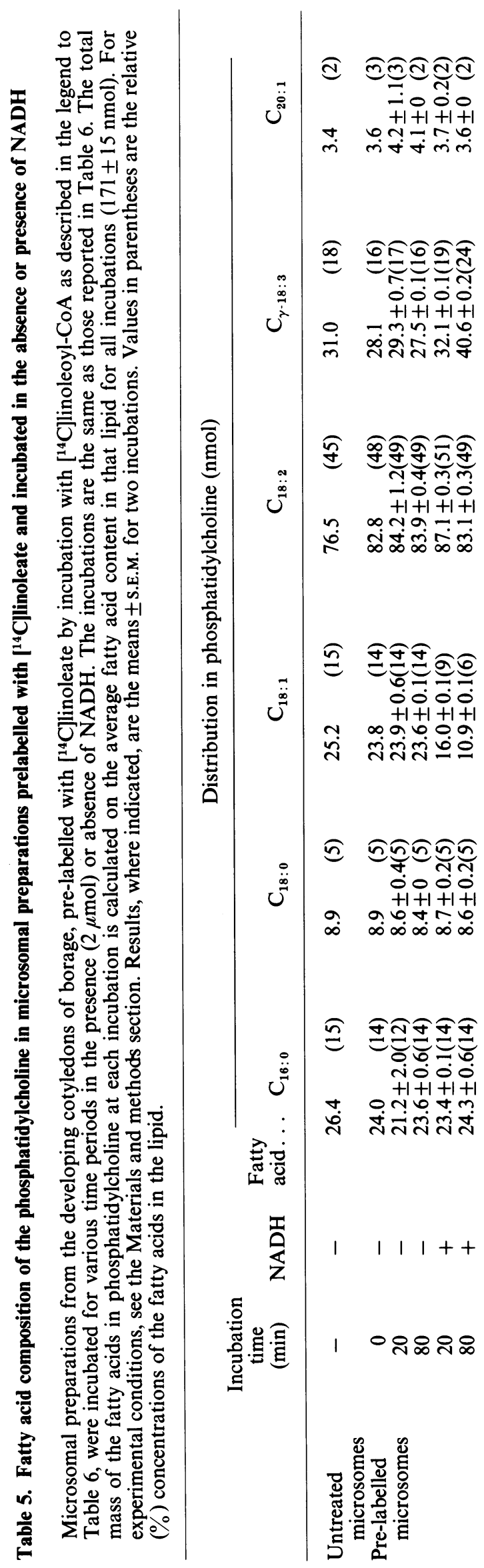


Table 6. Desaturation of $\left[{ }^{14} \mathrm{C} \mid\right.$ linoleate in a microsomal preparation incubated with $\left[{ }^{14} \mathrm{C}\right]$ linoleoyl-CoA in the presence of non-radioactive $\gamma$-linolenoyl-CoA

Microsomal preparations from the developing cotyledons of borage (equivalent to $192 \mathrm{nmol}$ of phosphatidylcholine) were incubated with $65 \mathrm{nmol}$ of $\left[{ }^{14} \mathrm{C}\right]$ linoleoyl-CoA, $100 \mathrm{nmol}$ of non-radioactive $\gamma$-linolenoyl-CoA and NADH $(2 \mu \mathrm{mol})$ at $25^{\circ} \mathrm{C}$ for 40 and $90 \mathrm{~min}$. For incubation conditions and analytical procedures, see the Materials and methods section. Results are, where indicated, the means \pm S.E.M. for two incubations.

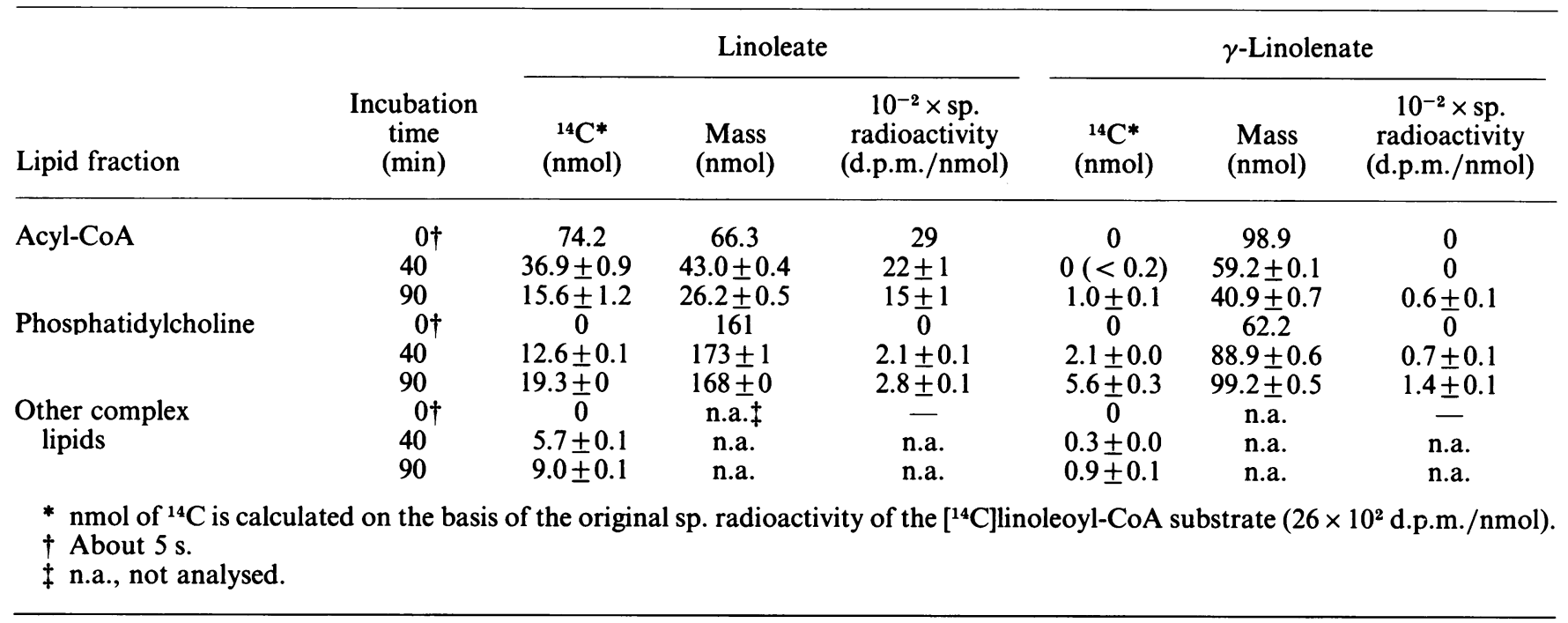

$\left[{ }^{14} \mathrm{C}\right]$ linoleate substrate) and small amounts were now present in the acyl-CoA fraction (equivalent to $1 \mathrm{nmol}$ of desaturated substrate). The mass of $\gamma$-linolenate in the acyl-CoA pool also decreased substantially during the times of incubation. The specific radioactivity of the $\gamma$-linolenate in phosphatidylcholine was twice that observed in the acyl-CoA. The results therefore strongly support the findings of the previous experiments that the synthesis of $\gamma$-linolenate in the developing cotyledons of borage utilizes the substrate linoleoyl phosphatidylcholine and not the acyl-CoA. It is also of interest to note that small amounts of $\gamma-\left[{ }^{14} \mathrm{C}\right]$ linolenate $(12 \%$ of the total $\gamma-\left[{ }^{14} \mathrm{C}\right]$ linolenate, Table 6) were present in lipids other than phosphatidylcholine after $\mathbf{4 0}$ min incubation and at a time when no radioactive $\gamma$-linolenate was found in the acyl-CoA fraction.

\section{DISCUSSION}

The developing seed cotyledons of Borago officinalis contained substantial quantities of $\gamma$-linolenate in their storage oils and polar lipids (Table 1). In experiments in vivo the cotyledons carried out a sequential desaturation of oleate and linoleate to yield $\gamma$-linolenate (Table 3). It was not possible, however, to ascertain the substrate for the $\Delta^{6}$-linoleate desaturase in these experiments with whole tissue. The maturating cotyledons from the seeds, however, yielded, when grown under suitable conditions, consistently active microsomal membrane preparations that were capable of synthesizing $\gamma$-linolenate from exogenously supplied linoleoyl-CoA. The desaturation of $\left[{ }^{14} \mathrm{C}\right]$ linoleoyl phosphatidylcholine in situ resulted in the formation of radioactive $\gamma$-linolenoyl phosphatidylcholine and indicated that the substrate for the linoleate $\Delta^{6}$-desaturase was probably the complex lipid phosphatidylcholine (Table 4). That phosphatidylcholine was in fact the major substrate for the $\Delta^{6}$-desaturase was confirmed in experiments in which the specific radioactivity of the $\gamma-\left[{ }^{14} \mathrm{C}\right]$ linolenate in acyl-CoA and phosphatidylcholine was measured during the desaturation of $\left[{ }^{14} \mathrm{C}\right]$ linoleate in the presence of non-radioactive $\gamma$-linolenoyl-CoA (Table 6). It is also interesting to note the changes in the mass of the fatty acids in phosphatidylcholine during desaturation (Table 5). There appears to be an inverse relationship between the desaturation of oleate and the appearance of $\gamma$-linolenate, whereas little change was observed in the linoleate content during this period of incubation. Since the $\gamma$-linolenate is being synthesized from oleate via linoleate (Table 3), this would indicate that, in the microsomal preparations, the activities of the oleate $\Delta^{12}$-desaturase and linoleate $\Delta^{6}$-desaturase enzymes are similar and hence, in the presence of NADH, the pool of linoleate is kept at a constant, steady-state, level. It is also of interest, in this context, that the fatty acid composition of the seed oils from a large number of different borage populations also appeared to exhibit an inverse relationship with the content of oleate and $\gamma$-linolenate (U. Nyman, personal communication). It would seem, therefore, that the regulation in borage of the oleate $\Delta^{\mathbf{1 2}}$-desaturase and linoleate $\Delta^{6}$-desaturase enzymes is closely related and that any induction in one is closely paralleled in the other.

Some of the $\gamma$-linolenate that was produced in the microsomes incubated with NADH was, certainly at the longer times, associated with complex lipids other than phosphatidylcholine (Table 4). Furthermore, a decrease in the radioactivity in phosphatidylcholine was also observed, and this occurred even under non-desaturating conditions (Table 4). These observations indicate that the $\gamma$-linolenate in phosphatidylcholine is being made available, perhaps via acyl exchange with a small pool of acyl-CoA (Stymne et al., 1983), for transfer to other lipids. It is of course a possibility that the linoleate $\Delta^{6}$-desaturase can utilize, to some extent, the fatty acid in complex lipids other than phosphatidylcholine. It is also noteworthy that radioactive $\gamma$-linolenate appeared in complex lipids before it was detected in acyl-CoA 
(Table 6), a result that is probably due to the reverse reaction of a CDP-choline:diacylglycerol cholinephosphotransferase, an enzyme known to operate in microsomal preparations from other oilseed species (Slack et al., 1985; Stobart \& Stymne, 1985a). Although acyl exchange between acyl-CoA and phosphatidylcholine was not measured per se in these experiments, it was nonetheless strongly evident, particularly in the final experiment in which there was a dramatic fall in the specific radioactivity of the linoleate in the acylCoA fraction (Table 6).

The $\Delta^{6}$-desaturase appears only to utilize as substrate the linoleate in position 2 of $s n$-phosphatidylcholine. The intramolecular specificity of the linoleate $\Delta^{6}$-desaturase was also evident from the fact that $\gamma$-linolenate was largely present in position 2 of endogenous, microsomal, $s n$-phosphatidylcholine, whereas linoleate was present in both positions, $s n-1$ and $s n-2$. The oleate $\Delta^{\mathbf{1 2}}$-desaturase in a high-linoleate variety of safflower (Carthamus tinctorius) was found to act on the oleate in positions $s n-1$ and -2 of microsomal phosphatidylcholine (Slack et al., 1979; Stobart \& Stymne, 1985b). In view of the distinction made by the linoleate $\Delta^{6}$-desaturase for the linoleate in positions $s n-1$ and -2 of phosphatidylcholine, it is possible that different desaturase enzymes exist that are positionally specific for substrate.

Contrary to our original speculation (see the Introduction) on the direct substrate for the linoleate $\Delta^{6}$. desaturase in plants, the experimental evidence unequivocably illustrates that the major substrate is linoleoyl phosphatidylcholine and that the acyl-CoA is a most unlikely candidate. It would seem, therefore, that perhaps all the desaturase enzymes in higher plants, and in particularly their seeds, that utilize oleate and linoleate, do so on a complex lipid substrate irrespective of where the centres of unsaturation are being inserted into the acyl chain. The formation of $\gamma$-linolenate in plants is particularly interesting since it is the only $\mathrm{C}_{18}$ polyunsaturated fatty acid whose synthesis can be compared directly with that of an animal counterpart. An explanation of why higher plants have evolved desaturase enzymes that utilize complex lipids would not appear to be based on a direct mechanistic reason. If one accepts teleological argument then one might conject that perhaps complex lipid substrates are more efficient in plants in that the desaturase enzymes are not then competing directly with other major reactions that utilize acyl-CoA.

We thank the Swedish Natural Research Council, the Swedish Council for Forestry and Agricultural Research and the National Swedish Board for Technical Development for financial support.

\section{REFERENCES}

Bligh, E. G. \& Dyer, W. J. (1959) Can. J. Biochem. Physiol. 37, 911-917

Brenner, R. R. (1981) Prog. Lipid Res. 20, 41-47

Browse, J. A. \& Slack, C. R. (1981) FEBS Lett. 131, 111-114

Griffiths, G., Stobart, A. K. \& Stymne, S. (1985) Biochem. J. 230, 379-388

Hawke, J. C. \& Stumpf, P. K. (1980) Arch. Biochem. Biophys. 203, 296-306

Hilditch, T. P. \& Williams, P. N. (1964) The Chemical Constitution of Natural Fats, Chapman and Hall, London Holloway, P. W. (1983) Enzymes 2nd Ed. 16, 63-83

Holman, R. T. \& Johnson, S. (1981) Prog. Lipid Res. 20, 67-73

Horrobin, D. F. \& Manku, M. S. (1983) in Fats for the Future (Brooker, S. G., Renwick, A., Hannan, S. F. \& Eyres, L.), pp. 99-101, Duromark, Auckland

Howling, D. Morris, L. J., Gurr, M. I. \& James, T. (1972) Biochim. Biophys. Acta 260, 10-19

Jones, A. V. M. \& Harwood, J. L. (1980) Biochem. J. 190, 851-854

Kates, M. (1964) J. Lipid Res. 5, 132-135

Murphy, D. J., Woodrow, I. E. \& Mukherjee, K. D. (1985) Biochem. J. 225, 267-270

Roughan, P. G., Mudd, J. B., McManus, T. T. \& Slack, C. R. (1979) Biochem. J. 184, 571-574

Sanchez, M., Nicholls, D. G. \& Brindley, D. N. (1973) Biochem. J. 132, 697-706

Slack, C. R., Roughan, P. G. \& Browse, J. A. (1979) Biochem. J. 179, 649-656

Slack, C. R., Campbell, L. C., Browse, J. A. \& Roughan, P. G. (1983) Biochim. Biophys. Acta 754, 10-20

Slack, C. R., Roughan, P. G., Browse, J. A. \& Gardiner, S. E. (1985) Biochim. Biophys. Acta 833, 438-448

Stobart, A. K. \& Stymne, S. (1985a) Biochem. J. 232, 217-221

Stobart, A. K. \& Stymne, S. (1985b) Planta 163, 119-125

Stobart, A. K., Stymne, S. \& Glad, G. (1983) Biochim. Biophys. Acta 754, 292-297.

Stymne, S. \& Appelqvist, L.-A. (1978) Eur. J. Biochem. 90, 223-229

Stymne, S. \& Glad, G. (1981) Lipids 16, 298-305

Stymne, S. \& Stobart, A. K. (1984a) Biochem. J. 223, 305-314

Stymne, S. \& Stobart, A. K. (1984b) Biochem. J. 220, 481-488

Stymne, S. \& Stobart, A. K. (1985) Biochim. Biophys. Acta 837, 239-250

Stymne, S. \& Stobart, A. K. (1986) in The Biochemistry of Plants: a Comprehensive Treatise (Stumpf, P. K., ed.), vol. 10, Chapter 9, Academic Press, New York, in the press

Stymne, S., Stobart, A. K. \& Glad, G. (1983) Biochim. Biophys. Acta 752, 198-208

Tetenyi, P., Hethelyi, I., Okuda, T. \& Imre, S. (1974) Herba Hung. 13, 61-71

Traitler, H., Winter, H., Richli, U. \& Ingenbleek, Y. (1984) Lipids 19, 923-928 